\title{
Cancer karyotypes: survival of the fittest
}

\author{
Joshua M. Nicholson and Daniela Cimini* \\ Department of Biological Sciences, Virginia Tech, Blacksburg, VA, USA
}

\section{Edited by:}

Samuel F. Bakhoum, Geisel School of Medicine at Dartmouth, USA

Reviewed by:

llio Vitale, Insitut Gustave Roussy, France

Kristina Godek, Dartmouth College USA

\section{*Correspondence:}

Daniela Cimini, Department of

Biological Sciences, Virginia Tech,

1981 Kraft Drive, Blacksburg, VA

24061, USA

e-mail: cimini@vt.edu
Cancer cells are typically characterized by complex karyotypes including both structural and numerical changes, with aneuploidy being a ubiquitous feature. It is becoming increasingly evident that aneuploidy per se can cause chromosome mis-segregation, which explains the higher rates of chromosome gain/loss observed in aneuploid cancer cells compared to normal diploid cells, a phenotype termed chromosomal instability (CIN). CIN can be caused by various mechanisms and results in extensive karyotypic heterogeneity within a cancer cell population. However, despite such karyotypic heterogeneity, cancer cells also display predominant karyotypic patterns. In this review we discuss the mechanisms of $\mathrm{CIN}$, with particular emphasis on the role of aneuploidy on CIN. Further, we discuss the potential functional role of karyotypic patterns in cancer.

Keywords: aneuploidy, karyotype, CIN, cancer, selection

\section{INTRODUCTION}

The karyotype of a human diploid somatic cell consists of 23 pairs of chromosomes, each encoding different genes essential for cellular function (Alberts et al., 2008). The gain of a single chromosome induces changes in the expression levels of hundreds to thousands of genes, including genes on the extra chromosome as well as genes on other chromosomes (Upender et al, 2004; Nicholson and Cimini, 2011). To limit the generation of aneuploidy in somatic cells, chromosome segregation is tightly regulated during mitosis (Musacchio and Salmon, 2007). Accordingly, chromosome mis-segregation in normal diploid cells occurs at rates below 1\% (Cimini et al., 1999; Minissi et al., 1999; Catalan et al., 2000). Cancer cells, which are generally aneuploid (Mitelman et al., 2011), display significantly higher rates of chromosome mis-segregation than normal diploid cells, a phenotype termed chromosomal instability (CIN). Most cancer cells also display chromosome structural instability (S-CIN), by which chromosome aberrations such as translocations, deletions, duplications, etc., occur with high frequencies. This type of instability is different from whole-chromosome mis-segregation/instability (WCIN), by which numerical defects, such as gains and losses of whole-chromosomes occur at high frequencies. For this review we focus on mechanisms of $\mathrm{W}$-CIN, hereafter referred to as CIN. Both the degree of aneuploidy and the rate of chromosome mis-segregation vary dramatically in cancer cells (Lengauer et al., 1998; Mitelman et al., 2011). Indeed, cancer karyotypes range from near-diploid $(2 \mathrm{~N} \pm$ few), to near-triploid ( $3 \mathrm{~N} \pm$ few), to near-tetraploid $(4 \mathrm{~N} \pm \mathrm{few})$, and the rates of chromosome mis-segregation in cancer cells, as measured by anaphase lagging chromosomes, range between 10 and $60 \%$ (Thompson and Compton, 2008; Ganem et al., 2009; Silkworth et al., 2009). In this review we will discuss the relationship between aneuploidy and CIN, the karyotype patterns observed in cancer cells, and the effects of such karyotypes on populations of cells or organisms.

\section{THE EFFECTS OF ANEUPLOIDY ON CIN}

Most cancer cells are aneuploid and display a CIN phenotype. CIN can be caused by numerous mechanisms [reviewed in (Nicholson and Cimini, 2011)], including transient spindle geometry defects (Ganem et al., 2009; Silkworth et al., 2009; Silkworth and Cimini, 2012), impaired microtubule dynamics (Bakhoum et al., 2009a,b), and, rarely, a dysfunctional mitotic checkpoint (Cahill et al., 1998; Sato et al., 2000; Haruki et al., 2001), although the mitotic checkpoint is functional in most cancer cells (Tighe et al., 2001). Additionally, abnormal centrosome replication (Lingle et al., 2005) and DNA replication stress (Burrell et al., 2013; Janssen and Medema, 2013) have been proposed as mechanisms of CIN. Abnormal centrosome replication is likely to induce CIN by causing transient spindle geometry defects (Silkworth and Cimini, 2012). However, in the study by Burrell et al. replication stress did not seem related to whole-chromosome mis-segregation. Another mechanism emerging as a cause of CIN in cancer cells is aneuploidy itself (Duesberg et al., 1998; Thompson and Compton, 2010; Sheltzer et al., 2011; Nicholson et al., 2012; Zhu et al., 2012), although there has been disagreement on whether this is really the case, with a number of reports concluding that CIN is an aneuploidy-independent trait (Storchova and Kuffer, 2008; Zasadil et al., 2013). We believe that such disagreements primarily arise from two main issues: (i) there is confusion on how CIN is defined; (ii) different studies measure CIN in different ways. CIN has been loosely defined as an elevated rate of chromosome missegregation (Lengauer et al., 1997), yet how elevated and compared to what is often unclear (Geigl et al., 2008). Geigl et al. (2008) suggest that CIN can be defined as a significant increase in the rate of chromosome mis-segregation compared to an appropriate control cell population. Further, appropriate statistical tests must be employed (Geigl et al., 2008). Given this definition, many reports identifying stable aneuploidies can be reinterpreted. Studies that use data available in the Mitelman database of cancer karyotypes (Storchova and Kuffer, 2008; Mitelman et al., 2011; Zasadil et al., 
2013) often rely on karyotypic analysis of small numbers (5-20) of cells per cancer, thus masking small rates of CIN that may be present (Adeyinka et al., 1998; Bridge et al., 2004). Other studies lack appropriate statistical analysis (Lengauer et al., 1997). Finally, stable is often used in relative terms. For instance, Roschke et al. (2002) identify stable aneuploid cancer cells in the presence of high rates of chromosome mis-segregation. These cells are considered stable because modal chromosome numbers do not deviate over time, despite deviations per chromosome of up to $20 \%$ at a given time (Roschke et al., 2002). The discrepancy between studies concluding that aneuploidy can cause CIN and those concluding that it does not may also stem from the method by which CIN is evaluated/measured in different studies. Many studies measure CIN by one of two methods: (i) performing karyotypic analysis (sometimes simply by chromosome count) at some point in time and measuring what fraction of the cell population possesses a chromosome number that deviates from the mode; (ii) performing FISH staining on interphase nuclei with chromosomespecific probes for two to three chromosomes and again evaluating what fraction of the cell population possesses a number of copies for those chromosomes that deviates from the mode. Neither of these methods really measures chromosome mis-segregation directly and both of them are very likely to underestimate the rates of chromosome mis-segregation occurring at each round of cell division. Because the gain or loss of a single chromosome represents a dramatic genetic change, whether a mis-segregation event can become evident as CIN using one of the methods described above will depend on a number of selective factors, including the specific chromosome that is lost or gained, the specific cell type studied, and the context (e.g., current karyotype, presence/absence of certain environmental conditions, etc.) in which the loss/gain occurs. In other words, cells that mis-segregate chromosomes may or may not survive, and therefore analysis of the karyotype in metaphase spreads or chromosome number in interphase nuclei may reveal a stable karyotype even in the presence of CIN. A more accurate way to measure CIN is by analyzing chromosome segregation in mitotic cells. Many labs have used this approach in recent years and found that CIN cells display higher rates of anaphase lagging chromosomes (chromosomes that lag behind at the cell equator while all other chromosomes segregate to the spindle poles, Figures 1A,B) compared to non-CIN cells (Thompson and Compton, 2008; Bakhoum et al., 2009a; Ganem et al., 2009; Silkworth et al., 2009). Anaphase lagging chromosomes, even when segregated to the correct daughter cell, still represent a mis-segregation event as they typically form micronuclei in the daughter cell (Cimini et al., 2002). Micronuclei have been shown to lead to both numerical and structural defects, including more anaphase lagging chromosomes (Crasta et al., 2012; He et al., 2012). Whereas the analysis of anaphase lagging chromosomes may be a better way to measure CIN, it may still be insufficient to determine the real rates of chromosome mis-segregation, as cases in which two sister chromatids segregate to the same spindle pole would go undetected. A good alternative approach to measure CIN would require the combination of more than one of the methods outlined above, such as, for instance, anaphase lagging chromosomes and interphase FISH or anaphase lagging chromosomes and karyotypic analysis. Alternatively, the analysis

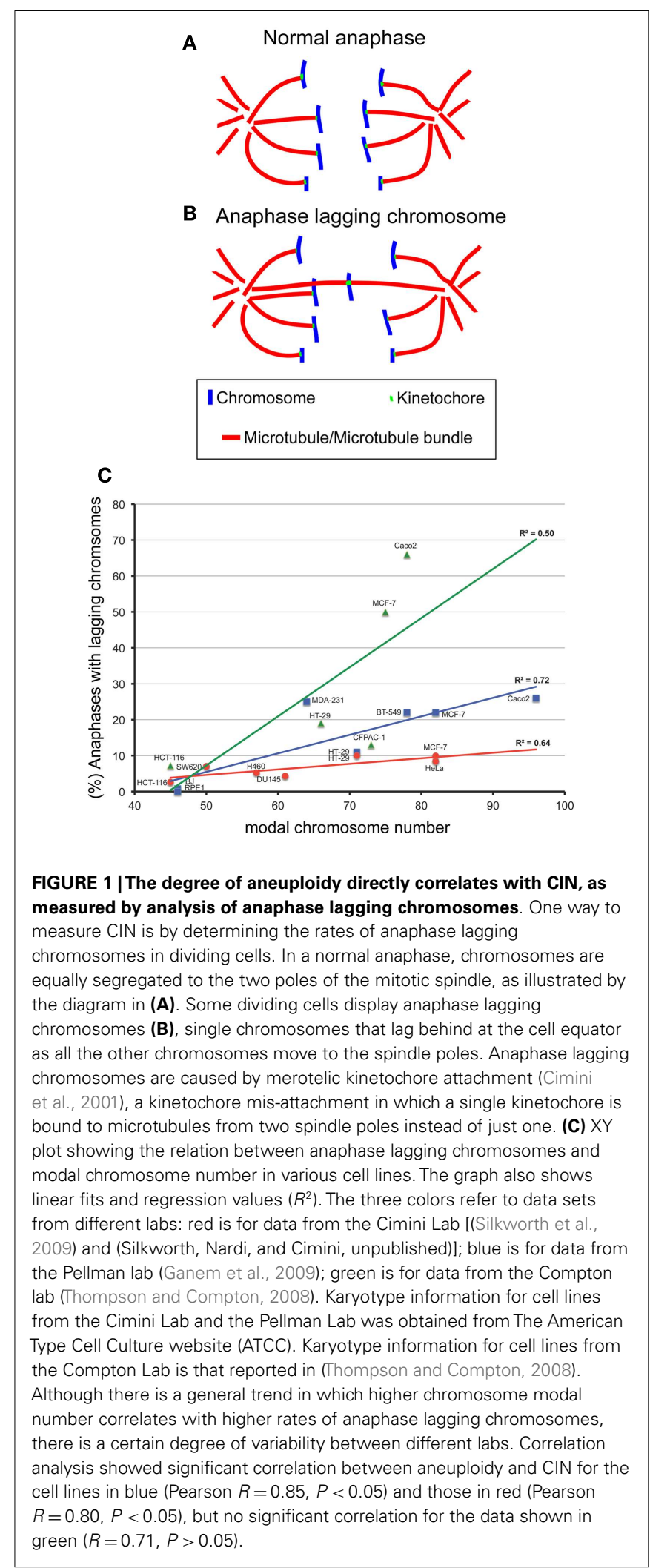

of anaphase lagging chromosomes (for all chromosomes) could be combined with analysis of chromosome segregation by FISH with chromosome-specific probes on anaphase cells and/or on 
binucleate cells in a cytokinesis-block assay (Cimini et al., 1999) and/or in the interphase ensuing cell division (Thompson and Compton, 2008).

Despite the significant difficulties of defining and measuring CIN, many investigators have shown that aneuploidy per se can cause CIN. Evidence supporting aneuploidy as a cause of chromosome mis-segregation was first suggested by correlations between the degree of aneuploidy and the degree of CIN in transformed Chinese hamster embryo cells and in colorectal cancer cell lines (Duesberg et al., 1998). Extending this analysis, we have plotted the rate of anaphase lagging chromosomes versus modal chromosome number and found a significant correlation (Figure 1C), indicating that a higher degree of aneuploidy (i.e., modal chromosome number significantly above 46) correlates with higher frequencies of chromosome mis-segregation (i.e., CIN). This, in turn, suggests that aneuploidy can induce chromosome mis-segregation due to an imbalance in the gene dosage (which may include many mitotic genes), such that a higher degree of aneuploidy will result in a more severe imbalance. More controlled analyses of the relationship between aneuploidy and CIN have revealed this relationship to be causal. For instance, studies in haploid yeast strains carrying specific disomies (aneuploidies) showed that aneuploidy induced high rates of chromosome mis-segregation (Sheltzer et al., 2011; Zhu et al., 2012), although not in all disomies tested (70\%, 9/13) (Sheltzer et al., 2011), and to varying degrees depending on the specific disomy (Zhu et al., 2012). Moreover, we have recently found that colorectal cancer cells carrying an extra copy of a chromosome (trisomy) also display higher rates of chromosome mis-segregation (anaphase lagging chromosomes and karyotypic heterogeneity) compared to diploid controls (Nicholson et al., 2012). Similar to yeast, we found the effects to vary depending on the specific trisomy (Nicholson et al., 2012). Finally, some studies have reported elevated rates of aneuploidy in somatic cells of individuals affected by congenital trisomies (Reish et al., 2006, 2011). Together, these findings indicate that aneuploidy causes chromosome mis-segregation in the majority of cases. However, not all aneuploidies are capable of doing so, and those that do, do not all do so to the same extent. Given that aneuploidy likely induces chromosome mis-segregation due to the genetic imbalance it generates, it is possible that the differences between different aneuploidies may simply depend on the gene content (both number and types of genes) carried by the aneuploid chromosome. Indeed, studies in disomic yeast show aneuploidy can induce an imbalance in the mitotic checkpoint genes MAD1 and MAD2 and in turn increase the rate of chromosome mis-segregation (Zhu et al., 2012). Cancer cells frequently over- or under-express genes involved in mitotic checkpoint and progression, which would be expected to result in an increase in chromosome mis-segregation (Anand et al., 2003; Babu et al., 2003; Yuan et al., 2006; Mondal et al., 2007; Sotillo et al., 2007, 2010; Diaz-Rodriguez et al., 2008; Logarinho et al., 2008; Baker et al., 2009; Ryan et al., 2012). Notably, the genes encoding proteins involved in mitotic checkpoint and progression are typically not mutated, but only mis-expressed in cancer (Cahill et al., 1999; Imai et al., 1999; Yamaguchi et al., 1999; Sato et al., 2000; Haruki et al., 2001). Another mechanism that may explain aneuploidy-induced CIN is a delay in timing of chromosome replication and/or condensation (DRT and DCT, respectively).
Pre-mitotic defects such as DRT and DCT have been shown to cause CIN (Smith et al., 2001; Chang et al., 2007; Grinberg-Rashi et al., 2010), and aneuploidy has been shown to induce DRT and DCT (Amiel et al., 1998, 1999; Kost-Alimova et al., 2004) in a chromosome-specific manner. This may depend on the presence of specific loci found on autosomes that control their own stability (Stoffregen et al., 2011; Thayer, 2012). Disrupting these loci leads to a dramatic increase in micro-nucleated cells (Donley et al., 2013), a common outcome of anaphase lagging chromosomes (Cimini et al., 2002) and a common defect of cancer cells (Bhatia and Kumar, 2012). Nonetheless, more work will undoubtedly need to be performed to fully understand how aneuploidy induces CIN.

\section{THE CANCER KARYOTYPE}

As described above, most cancer cells display rates of anaphase lagging chromosomes ranging between 10 and 60\% (Thompson and Compton, 2008; Ganem et al., 2009; Silkworth et al., 2009). Considering that in $1 \mathrm{~cm}^{3}$ of tumor tissue there are approximately $10^{9}$ cells, chromosome mis-segregation rates of $10-60 \%$ could theoretically produce 100,000,000-600,000,000 cells with different karyotypes although it is not known whether these missegregation rates identified in cultured cells represent the actual chromosome mis-segregation rates occurring within the tumor. Moreover, although karyotypic analysis has revealed extensive intratumor heterogeneity (Heppner, 1984; Gerlinger et al., 2012), cancer karyotypes are not totally random (Winge, 1930; Levan, 1956; Makino, 1956; Hauschka and Levan, 1958; Roschke et al., 2002; Nicholson and Duesberg, 2009). Indeed, karyotypic analysis of thousands of cancers has revealed the existence of karyotypic patterns, with aneuploidies that are recurrently found in several different cancer types (Table 1), and others that are specific to individual tumors and tissues/organs of origin (Table 1) (Gebhart and Liehr, 2000; Beroukhim et al., 2010; Mitelman et al., 2011; Ozery-Flato et al., 2011; Cai et al., 2012). For instance, extra copies of 1q, 3q, 8q, 7, and 20 are found in numerous different cancers at least $25 \%$ of the time (Table 1). And in general, small, gene poor chromosomes are lost across all cancers (Duijf et al., 2012). On the other hand, gain of chromosome 13 is frequently seen in colorectal cancer, but is rarely observed in other cancer types (Bomme et al., 1994; Bardi et al., 1995) (Table 1). Similarly, gain of chromosome 21 is frequent in acute lymphoblastic leukemia, but not in other cancers (Table 1). Karyotype alterations are apparent not only spatially but also temporally, with certain chromosomes being gained or lost earlier than others during cancer progression (Bardi et al., 1995; Fabarius et al., 2002; Ly et al., 2011; Tabach et al., 2011; Ried et al., 2012). What are the factors that generate karyotypic patterns in cancer? Some studies have reported that aneuploidy and CIN can result in loss of heterozygosity for p53 (Matsumura et al., 1992; Blount et al., 1994; Baker et al., 2009) or Rb (Cavenee et al., 1983), supporting the idea that karyotypic changes lead to gain of oncogenes and loss of tumor suppressor genes. Whereas this may be true in some cases, findings from other studies argue against this conclusion. For example, in glioma about half of significant copy number changes are not associated with oncogenes or tumor suppressor genes (Beroukhim et al., 2007). Moreover, if the significance of aneuploidy was exclusively related to its role in promoting the 
Table 1 | Recurrent aneuploidies in cancers from different sites.

\begin{tabular}{|c|c|c|c|}
\hline \multirow[t]{2}{*}{ Cancer type } & \multicolumn{2}{|c|}{ Recurrent aneuploidies } & \multirow[t]{2}{*}{ Cases } \\
\hline & Gains & Losses & \\
\hline $\begin{array}{l}\text { Acute lymphoblastic } \\
\text { leukemia }\end{array}$ & 21 & - & 533 \\
\hline Breast cancer & $1 q, 8 q, 17 q, 20$ & $\mathbf{8 p}, 16 q, 17 p$ & 2,108 \\
\hline Cervical cancer & $3 q$ & NA & 526 \\
\hline Colorectal cancer & $7, \mathbf{8 q}, 13,20$ & $\mathbf{8 p}, \mathbf{1 7 p}, 18$ & 989 \\
\hline Esophageal cancer & $\begin{array}{l}\mathbf{1 q}, \mathbf{3 q}, 5 p, \mathbf{7} \\
\mathbf{8 q}, 12 p, \mathbf{2 0}\end{array}$ & $\begin{array}{l}\mathbf{3 p}, 4,5 q, 8 p \\
13,18 q, 19\end{array}$ & 402 \\
\hline Gastric cancer & $8 q, 20$ & - & 777 \\
\hline Glioma & 7 & $1 p, 19 q$ & 591 \\
\hline $\begin{array}{l}\text { Head and neck } \\
\text { cancer }\end{array}$ & $3 q, 8 q, 11 q$ & $3 p, 8 p$ & 714 \\
\hline Hepatic cancer & $1 q, 8 q$ & $\begin{array}{l}4 q, \mathbf{8 p}, 13 \\
16 q, \mathbf{1 7 p}\end{array}$ & 903 \\
\hline Medulloblastoma & 7, $17 q$ & $17 p$ & 1,153 \\
\hline Pancreatic cancer & $\begin{array}{l}\text { 1q, 3q, } 5 p, 7 p \\
\mathbf{8 q}, 20 q\end{array}$ & $\begin{array}{l}3 \mathbf{p}, 4 q, 6,8 \mathbf{p} \\
9 p, 17 \mathbf{p}, 18,22\end{array}$ & 327 \\
\hline
\end{tabular}

Cancers display common recurrent aneuploidies (indicated in bold), as well as recurrent aneuploidies that are tumor - and tissue/organ of origin-specific. Data are adapted from the arrayMap website [Www.arraymap.com; (Cai et al., 2012)] and represent gains or losses that occur in at least $25 \%$ of cases analyzed.

gain of oncogenes or loss of tumor suppressor genes, then one could not explain the individuality of cancer karyotypes per site of origin, given that oncogene and tumor suppressor loci are the same in all human somatic cells. Instead, the fact that the tissue/site of origin is important in determining karyotypic patterns in cancer cells indicates that selection of specific karyotypes must also depend on the specific biology and physiology of cells from different tissues/organs. Indeed, microarray analysis of cells from different tissues shows tissue-specific gene expression patterns in normal diploid cells (Hsiao et al., 2001; Liu et al., 2008). These fixed expression patterns allow cells with the same karyotypes to define different organs and tissues. Such fixed expression patterns will also make it so that the same aneuploidy in different tissues has different effects. Indeed, identical trisomies in different cell types result in different expression patterns for genes both on and off the aneusomic chromosome (Upender et al., 2004). For instance, trisomy 3 in colorectal cancer cells causes significant changes in expression of genes located on chromosomes 1p, 3, 10p, and Y while trisomy 3 in immortalized mammary epithelial cells causes significant changes in expression of genes located on chromosomes 2p, 3, 6q, and 18q (Upender et al., 2004). In further support of the idea that the effect of aneuploidy is cell type-specific is the observation that individuals with trisomy 21 (Down's syndrome) show an increase in hematological cancers, but decreased incidence of solid tumors compared to diploid individuals (Rabin and Whitlock, 2009). Interestingly, gain of chromosome 21 is the most common karyotype alteration in acute lymphoblastic leukemia (Table 1), but is infrequent in glioblastoma, breast, and colorectal cancer. The enhanced tumorigenic potential conferred by the same aneuploidy in certain tissues but not in others underscores the importance of both the specific karyotypes and the context in which such karyotypes are found.

\section{THE ADAPTIVE POTENTIAL OF ANEUPLOIDY}

The large-scale genomic changes caused by aneuploidy, which alters the expression of hundreds to thousands of genes (Thayer, 1996; Pollack et al., 2002; Upender et al., 2004; Gao et al., 2007), can limit the growth of aneuploid cells under standard environmental conditions (Torres et al., 2007). Under certain circumstances, however, these same changes can confer enhanced fitness (Pavelka et al., 2010; Tang et al., 2011). For example, in Candida albicans, formation of isochromosome $5 \mathrm{~L}$ causes azole resistance via upregulation of the genes ERG11 and TAC1 (Selmecki et al., 2008). Similarly, in aneuploid Saccharomyces cerevisiae, the gain of chromosome XIII confers resistance against the DNA damaging agent 4-NQO (Pavelka et al., 2010) due to the overexpression of ATR1, a gene on chromosome XIII whose overexpression is sufficient to confer resistance to 4-NQO (Mack et al., 1988; Pavelka et al., 2010). The adaptive potential of aneuploidy in yeast is well demonstrated for many other exogenous stresses (Selmecki et al., 2006, 2009; Pavelka et al., 2010; Tang et al., 2011; Rancati and Pavelka, 2013). Aneuploidy has also been proposed as a mechanism that can counteract the accumulation of deleterious mutations, a process termed Muller's Ratchet (Muller, 1964; Bignold, 2007a,b; Torres et al., 2008; Vincent, 2011; Duesberg and McCormack, 2013). An elegant study by Rancati et al. (2008) supports this idea showing that aneuploidy can rescue deleterious mutations in a conserved cytokinesis motor. Similarly, the gain of chromosome VI in yeast is lethal due to the overexpression of the highly dosage-sensitive gene encoding $\beta$-tubulin (TUB2) (Katz et al., 1990; Torres et al., 2007; Anders et al., 2009); however, gain of chromosome XIII, which encodes $\alpha$-tubulin, restores the balance and the double disome VI/XIII is viable (Anders et al., 2009). The findings in yeast extend to many other situations, including naturally occurring chromosomal imbalances, and aneuploidy in cancerous and non-cancerous mammalian cells. For instance, immortalized colon epithelial cells with trisomy 7 out-compete immortalized diploid colon cells in serum-free media (Ly et al., 2011). Likewise, tyrosinemia-induced stress in mouse liver can be overcome by the emergence of aneuploid hepatocytes lacking chromosome 16 (Duncan et al., 2012a). Chromosome 16 carries the homogentisic acid dioxygenase (HGD) gene and loss of HGD in a heterozygous background causes resistance to tyrosinemiainduced hepatic injury (Duncan et al., 2012a). Although the exact mechanisms have been hard to elucidate due to the complexity of cancer karyotypes, the karyotype-phenotype relationship has also been proposed as a mechanism for adaptation in cancer (Duesberg et al., 2007). Indeed, cancer cells that display high rates of CIN, and consequent karyotypic heterogeneity, display intrinsic drug resistance to a wide range of kinase inhibitors (Lee et al., 2011) and other drugs (Li et al., 2005). There have been attempts to selectively inhibit proliferation of aneuploid cells with specific drugs (Tang et al., 2011), however such drugs have not proven effective in other aneuploid cells, even at the highest tolerated dose ( $\mathrm{Li}$ et al., 2012). In summary, the effects of aneuploidy on the adaptive potential of cancer cells are twofold; (1) specific aneuploidies can confer resistance due to specific changes in gene expression and 
(2) aneuploidy causes chromosome mis-segregation, thus leading to new karyotypes, some of which will confer selective advantage under specific conditions and in specific contexts.

\section{THE UNIQUE CASE OF B-CHROMOSOMES: A NATURALLY OCCURRING CHROMOSOMAL IMBALANCE}

Chromosomal imbalance is generally thought to be associated with disease, which is the case for trisomies causing congenital syndromes, such as Down (trisomy 21), Patau (trisomy 13), and Edwards (trisomy 18) syndrome, or for the high levels of aneuploidy associated with cancer. However, high rates of aneuploidy have also been observed in healthy human tissues, such as liver (Duncan et al., 2012b) and brain (Rehen et al., 2005), in which aneuploidy has been argued to confer adaptive potential (Kingsbury et al., 2005; Duncan et al., 2012a; Bushman and Chun, 2013). Moreover, there exist examples of chromosomal imbalance that simply reflect species-specific evolutionary adaptations. A common example of this is the evolution of sex-specific chromosomes with different genetic content, or the case of species with $\mathrm{X} 0$ sex determination system, or the even more extreme case of certain insect species in which a complete set of chromosomes is eliminated (haplodiploidy) in males [for a review on sex determination see (Sumner, 2003)]. Finally, a very unique case is represented by Bchromosomes, extra chromosomes found in the karyotype of wild populations of many animal, fungi, and plant species (Camacho et al., 2000). B-chromosomes are unique supernumerary chromosomes ranging in size and structure from a small fragment to the largest chromosome in the karyotype (Jones and Diez, 2004; Gregory, 2005). While unique, B-chromosomes share some homology with the A-chromosomes (chromosomes of the standard, normal karyotype) and are consequently thought to have derived from them (Jones and Rees, 1982; Martis et al., 2012). The derivation of new chromosomes from the normal chromosome complement is similar to the evolution of marker chromosomes in cancer. Moreover, when present, B-chromosomes can vary in number in different individuals of the same species, thus representing a clear example of chromosomal imbalance similar to aneuploidy. Given the deleterious effect that extra chromosomes can have in many different cell-types and organisms, it is surprising that so many species can maintain these extra chromosomes in their genome. As with aneuploidy, however, this may be possible if B-chromosomes were maintained through a balance between negative effect and adaptive potential. B-chromosomes are largely heterochromatic but they can affect the expression levels of genes on the A-chromosomes (Kirk and Jones, 1970; Ayonoadu and Rees, 1971), and accordingly, induce phenotypic changes such as different sex traits in cichlids (Yoshida et al., 2011) or leaf color in corn (Staub, 1987). The mechanism responsible for maintaining B-chromosomes in the karyotype is still debated (Camacho et al., 2000), but it is clear that, at least in some cases, B-chromosomes can act heterotically (i.e., enhance fitness) and confer an adaptive advantage to the individual carrying them compared to individuals whose karyotype lacks B-chromosomes, much like aneuploidy in yeast grown under stressful conditions. For instance, Avena sativa with B-chromosomes shows resistance to rust (Dherawattana and Sadanaga, 1973) and the fungus Nectria haematococca with Bchromosomes is resistant to antibiotics (Miao et al., 1991a,b).
Similarly, the plant Allium schoenoprasum with B-chromosomes displays higher survival rates in natural environments than $A$. schoenoprasum without B-chromosomes (Holmes and Bougourd, 1989), due to the ability of B-chromosomes to enhance the germination rate in drought conditions (Plowman and Bougourd, 1994). Alternatively, B-chromosomes have been thought to be maintained via a "parasitic-selfish model." In this model, Bchromosomes are detrimental to the carriers (Camacho et al., 2000). In reality, these two models can be unified in a framework in which B-chromosomes, like aneuploidy for a cell, are generally detrimental to the individual, but can confer an adaptive advantage in certain environmental conditions. In support of this model is the observation that in the British grasshopper Myrmeleotettix maculatus specific B-chromosomes occur in warm, dry environments, and are scarce or absent in humid, cooler localities (Robinson and Hewitt, 1976).

\section{CONCLUSION}

That cancer cells are typically aneuploid is currently a widely acknowledged fact. However, there is still confusion on whether most cancer cells also display CIN (i.e., increased rates of chromosome mis-segregation compared to normal cells) or whether this is a less common phenotype. Here we described how the way CIN is typically evaluated is likely to underestimate the actual rates of chromosome mis-segregation in cancer cells. Moreover, emerging evidence indicates that aneuploidy itself promotes CIN. Thus, we argue that CIN, like aneuploidy, is a common feature of cancer cells. One point of confusion about CIN is the fact that cancer karyotypes are not totally random, but rather karyotypic patterns can be identified in various cancers, thus raising the question of how can a cell population mis-segregate chromosomes at high rates and yet display relatively stable karyotypes. We believe that the answer to this question is that karyotype patterns evolve due to the selective pressure within the cancer-specific microenvironment. This will lead to selection of aneuploidies that are common to various cancer types (e.g., chromosomes carrying genes important for cell survival and proliferation in all cell-types) as well as aneuploidies that are specific to individual cancers (e.g., chromosomes carrying genes that are important for cell survival and/or proliferation within a certain tissue/organ). The selection of cancer karyotypes due to the effects they confer (i.e., enhanced fitness in specific environmental conditions/contexts) appear to be the same in naturally occurring chromosomal imbalances (e.g., B-chromosomes), thus indicating that changes in chromosome number represent a natural mechanism of adaptation and evolution or simply stated: survival of the fittest karyotype leads to evolution of cancer, populations, and species.

\section{ACKNOWLEDGMENTS}

We would like to thank all the members of the Cimini Lab for useful discussion and helpful comments. We also thank Giulia Rancati (Institute of Medical Biology, A-STAR, Singapore) for providing useful information and reference to scientific literature, and Neil Ganem (Dana Farber Cancer Institute, Harvard Medical School, Boston, MA, USA) for providing clarifications on published data. Work in the Cimini Lab is supported by NSF grant MCB-0842551 and HFSP grant RGY0069/2010. 


\section{REFERENCES}

Adeyinka, A., Mertens, F., Idvall, I., Bondeson, L., Ingvar, C., Heim, S., et al. (1998). Cytogenetic findings in invasive breast carcinomas with prognostically favourable histology: a less complex karyotypic pattern? Int. J. Cancer 79, 361-364. doi:10.1002/(SICI)10970215(19980821)79:4\&lt;361::AIDIJC9\&gt;3.0.CO;2-T

Alberts, B., Bray, D., Lewis, J., Raff, M., Roberts, K., and Watson, J. D. (2008). Molecular Biology of the Cell. New York: Garland Publishing, Inc.

Amiel, A., Avivi, L., Gaber, E., and Fejgin, M. D. (1998). Asynchronous replication of allelic loci in Down syndrome. Eur. J. Hum. Genet. 6, 359-364. doi:10.1038/sj.ejhg.5200199

Amiel, A., Korenstein, A., Gaber, E., and Avivi, L. (1999). Asynchronous replication of alleles in genomes carrying an extra autosome. Eur. J. Hum. Genet. 7, 223-230. doi:10.1038/sj.ejhg.5200267

Anand, S., Penrhyn-Lowe, S., and Venkitaraman, A. R. (2003). AURORA-A amplification overrides the mitotic spindle assembly checkpoint, inducing resistance to Taxol. Cancer Cell 3, 51-62. doi:10.1016/S15356108(02)00235-0

Anders, K. R., Kudrna, J. R., Keller, K. E., Kinghorn, B., Miller, E. M., Pauw, D., et al. (2009). A strategy for constructing aneuploid yeast strains by transient nondisjunction of a target chromosome. BMC Genet. 10:36. doi:10.1186/1471-2156-10-36

Ayonoadu, U. W., and Rees, H. (1971). The effects of $\mathrm{B}$ chromosomes on the nuclear phenotype in root meristems of maize. Heredity 27, 365-383. doi:10.1038/hdy.1971.101

Babu, J. R., Jeganathan, K. B., Baker, D. J., Wu, X., Kang-Decker, N., and Van Deursen, J. M. (2003). Rael is an essential mitotic checkpoint regulator that cooperates with Bub3 to prevent chromosome missegregation. J. Cell Biol. 160, 341-353. doi:10.1083/jcb.200211048

Baker, D. J., Jin, F., Jeganathan, K. B., and Van Deursen, J. M. (2009). Whole chromosome instability caused by Bubl insufficiency drives tumorigenesis through tumor suppressor gene loss of heterozygosity. Cancer Cell 16, 475-486. doi:10.1016/j.ccr.2009.10.023

Bakhoum, S. F., Genovese, G., and Compton, D. A. (2009a). Deviant kinetochore microtubule dynamics underlie chromosomal instability. Curr. Biol. 19, 1937-1942. doi:10.1016/j.cub.2009.09.055
Bakhoum, S. F., Thompson, S. L., Manning, A. L., and Compton, D. A. (2009b). Genome stability is ensured by temporal control of kinetochoremicrotubule dynamics. Nat. Cell Biol. 11,27-35. doi:10.1038/ncb1809

Bardi, G., Sukhikh, T., Pandis, N., Fenger, C., Kronborg, O., and Heim, S. (1995). Karyotypic characterization of colorectal adenocarcinomas. Genes Chromosomes Cancer 12, 97-109. doi:10.1002/gcc.2870120204

Beroukhim, R., Getz, G., Nghiemphu, L., Barretina, J., Hsueh, T., Linhart, D., et al. (2007). Assessing the significance of chromosomal aberrations in cancer: methodology and application to glioma. Proc. Natl. Acad. Sci. U.S.A. 104, 20007-20012. doi:10.1073/pnas.0710052104

Beroukhim, R., Mermel, C. H., Porter, D., Wei, G., Raychaudhuri, S., Donovan, J., et al. (2010). The landscape of somatic copy-number alteration across human cancers. Nature 463, 899-905. doi:10.1038/nature08822

Bhatia, A., and Kumar, Y. (2012). Cancer cell micronucleus: an update on clinical and diagnostic applications. APMIS doi:10.1111/apm.12033. [Epub ahead of print].

Bignold, L. P. (2007a). Aneuploidy as a counter to "Muller's ratchet" in cancer cells. Cancer Genet. Cytogenet. 178, 173-174. doi:10.1016/ j.cancergencyto.2007.07.015

Bignold, L. P. (2007b). Variation, "evolution", immortality and genetic instabilities in tumour cells. Cancer Lett. 253, 155-169. doi:10.1016/j.canlet.2006.12.007

Blount, P. L., Galipeau, P. C., Sanchez, C. A., Neshat, K., Levine, D. S., Yin, J., et al. (1994). 17p allelic losses in diploid cells of patients with Barrett's esophagus who develop aneuploidy. Cancer Res. 54, 2292-2295.

Bomme, L., Bardi, G., Pandis, N. Fenger, C., Kronborg, O., and Heim, S. (1994). Clonal karyotypic abnormalities in colorectal adenomas: clues to the early genetic events in the adenomacarcinoma sequence. Genes Chromosomes Cancer 10, 190-196. doi:10.1002/gcc.2870100307

Bridge, R. S., Bridge, J. A., Neff, J. R., Naumann, S., Althof, P., and Bruch, L. A. (2004). Recurrent chromosomal imbalances and structurally abnormal breakpoints within complex karyotypes of malignant peripheral nerve sheath tumour and malignant triton tumour: a cytogenetic and molecular cytogenetic study. J. Clin. Pathol. 57, 1172-1178. doi:10.1136/jcp.2004.019026
Burrell, R. A., McClelland, S. E., Endesfelder, D., Groth, P., Weller M. C., Shaikh, N., et al. (2013). Replication stress links structural and numerical cancer chromosomal instability. Nature 494, 492-496. doi:10.1038/nature11935

Bushman, D. M., and Chun, J. (2013). The genomically mosaic brain: aneuploidy and more in neural diversity and disease. Semin. Cell Dev. Biol. 4, 357-369. doi:10.1016/j.semcdb.2013.02.003

Cahill, D. P., Da Costa, L. T., CarsonWalter, E. B., Kinzler, K. W. Vogelstein, B., and Lengauer, C. (1999). Characterization of MAD2B and other mitotic spindle checkpoint genes. Genomics 58, 181-187. doi:10.1006/geno.1999.5831

Cahill, D. P., Lengauer, C., Yu, J., Riggins, G. J., Willson, J. K. V., Markowitz, S. D., et al. (1998). Mutations of mitotic checkpoint genes in human cancers. Nature 392 300-303. doi:10.1038/32688

Cai, H., Kumar, N., and Baudis, M. (2012). arrayMap: a reference resource for genomic copy number imbalances in human malignancies. PLoS ONE 7:e36944. doi:10.1371/journal.pone.0036944

Camacho, J. P., Sharbel, T. F., and Beukeboom, L. W. (2000). B-chromosome evolution. Philos. Trans. R. Soc Lond. B Biol. Sci. 355, 163-178. doi:10.1098/rstb.2000.0556

Catalan, J., Surralles, J., Falck, G. C., Autio, K., and Norppa, H. (2000). Segregation of sex chromosomes in human lymphocytes. Mutagenesis 15, 251-255. doi:10.1093/mutage/15.3.251

Cavenee, W. K., Dryja, T. P., Phillips, R. A., Benedict, W. F., Godbout, R., Gallie, B. L., et al. (1983). Expression of recessive alleles by chromosomal mechanisms in retinoblastoma. Nature 305, 779-784. doi:10.1038/305779a0

Chang, B. H., Smith, L., Huang, J., and Thayer, M. (2007). Chromosomes with delayed replication timing lead to checkpoint activation, delayed recruitment of Aurora B and chromosome instability. Oncogene 26, 1852-1861. doi:10.1038/sj.onc. 1209995

Cimini, D., Fioravanti, D., Salmon, E. D., and Degrassi, F. (2002). Merotelic kinetochore orientation versus chromosome mono-orientation in the origin of lagging chromosomes in human primary cells. J. Cell. Sci. 115, 507-515.

Cimini, D., Howell, B., Maddox, P., Khodjakov, A., Degrassi, F., and Salmon, E. D. (2001). Merotelic kinetochore orientation is a major mechanism of aneuploidy in mitotic mammalian tissue cells. J. Cell Biol. 153, 517-527. doi:10.1083/jcb.153.3.517

Cimini, D., Tanzarella, C., and Degrassi, F. (1999). Differences in malsegregation rates obtained by scoring ana-telophases or binucleate cells. Mutagenesis 14, 563-568. doi:10.1093/mutage/14.6.563

Crasta, K., Ganem, N. J., Dagher, R., Lantermann, A. B., Ivanova, E. V., Pan, Y., et al. (2012). DNA breaks and chromosome pulverization from errors in mitosis. Nature 482, 53-58. doi:10.1038/nature10802

Dherawattana, A., and Sadanaga, K. (1973). Cytogenetics of a crown, rust-resistant hexaploid oat with $42+2$ fragment chromosomes. Crop Sci. 13, 591-594. doi:10.2135/cropsci1973.0011183X 001300060002x

Diaz-Rodriguez, E., Sotillo, R., Schvartzman, J. M., and Benezra, R. (2008). $\mathrm{Hecl}$ overexpression hyperactivates the mitotic checkpoint and induces tumor formation in vivo. Proc. Natl. Acad. Sci. U.S.A. 105, 16719-16724. doi:10.1073/pnas.0803504105

Donley, N., Stoffregen, E. P., Smith, L., Montagna, C., and Thayer, M. J. (2013). Asynchronous replication, mono-allelic expression, and long range Cis-effects of ASAR6. PLoS Genet. 9:e1003423. doi:10.1371/journal.pgen.1003423

Duesberg, P., Li, R., Sachs, R., Fabarius, A., Upender, M. B., and Hehlmann, R. (2007). Cancer drug resistance: the central role of the karyotype. Drug Resist. Updat. 10, 51-58. doi:10.1016/j.drup.2007.02.003

Duesberg, P., and McCormack, A. (2013). Immortality of cancers: a consequence of inherent karyotypic variations and selections for autonomy. Cell Cycle 12, 783-802. doi:10.4161/cc.23720

Duesberg, P., Rausch, C., Rasnick, D., and Hehlmann, R. (1998). Genetic instability of cancer cells is proportional to their degree of aneuploidy. Proc. Natl. Acad. Sci. U.S.A. 95, 13692-13697.

Duijf, P. H., Schultz, N., and Benezra, R. (2012). Cancer cells preferentially lose small chromosomes. Int. J. Cancer 132, 2316-2326. doi:10.1002/ijc. 27924

Duncan, A. W., Hanlon Newell, A. E., Bi, W., Finegold, M. J., Olson, S. B., Beaudet, A. L., et al. (2012a). Aneuploidy as a mechanism for stress-induced liver adaptation. J. Clin. Invest. 122, 3307-3315. doi:10.1172/JCI64026 
Duncan, A. W., Hanlon Newell, A. E., Smith, L., Wilson, E. M., Olson, S. B., Thayer, M. J., et al. (2012b). Frequent aneuploidy among normal human hepatocytes. Gastroenterology 142, 25-28. doi:10.1053/j.gastro.2011. 10.029

Fabarius, A., Willer, A., Yerganian, G., Hehlmann, R., and Duesberg, P. (2002). Specific aneusomies in Chinese hamster cells at different stages of neoplastic transformation, initiated by nitrosomethylurea. Proc. Natl. Acad. Sci. U.S.A.99, 6778-6783. doi:10.1073/pnas.25167 0699

Ganem, N. J., Godinho, S. A., and Pellman, D. (2009). A mechanism linking extra centrosomes to chromosomal instability. Nature 460, 278-282. doi:10.1038/nature08136

Gao, C., Furge, K., Koeman, J., Dykema, K., Su, Y., Cutler, M. L., et al. (2007). Chromosome instability, chromosome transcriptome, and clonal evolution of tumor cell populations. Proc. Natl. Acad. Sci. U.S.A. 104, doi:10.1073/pnas.0700631104

Gebhart, E., and Liehr, T. (2000). Patterns of genomic imbalances in human solid tumors. Int. J. Oncol. 16, 383-399.

Geigl, J. B., Obenauf, A. C., Schwarzbraun, T., and Speicher, M. R. (2008). Defining 'chromosomal instability'. Trends Genet. 24, 64-69. doi:10.1016/j.tig.2007. 11.006

Gerlinger, M., Rowan, A. J., Horswell, S., Larkin, J., Endesfelder, D., Gronroos, E., et al. (2012). Intratumor heterogeneity and branched evolution revealed by multiregion sequencing. N. Engl. J. Med. 366, 883-892. doi:10.1056/ NEJMoa1113205

Gregory, T. R. (2005). The Evolution of the Genome. Burlington, MA: Elsevier Academic.

Grinberg-Rashi, H., Cytron, S., GelmanKohan, Z., Litmanovitch, T., and Avivi, L. (2010). Replication timing aberrations and aneuploidy in peripheral blood lymphocytes of breast cancer patients. Neoplasia 12, 668-674.

Haruki, N., Saito, H., Harano, T., Nomoto, S., Takahashi, T., Osada, H., et al. (2001). Molecular analysis of the mitotic checkpoint genes BUB1, BUBR1 and BUB3 in human lung cancers. Cancer Lett. 162, 201-205. doi:10.1016/S03043835(00)00675-3

Hauschka, T., and Levan, A. (1958). Cytologic and functional characterization of single cell clones isolated from the Krebs-2 and Ehrlich ascites tumors. J. Natl. Cancer Inst. 21, 77-111.

He, B., Hinman, A., and Cimini, D. (2012). Chromosomes mis-segregated into micronuclei trigger chromosomal instability by further mis-segregating at subsequent mitoses. Mol. Biol. Cell 23(Suppl.). [Abstract No. 1928].

Heppner, G. H. (1984). Tumor heterogeneity. Cancer Res. 44, 2259-2265.

Holmes, D. S., and Bougourd, S. M. (1989). B-chromosome selection in Allium schoenoprasum. I. Natural populations. Heredity 63, 83-87. doi:10.1038/hdy.1989.78

Hsiao, L. L., Dangond, F., Yoshida, T., Hong, R., Jensen, R. V., Misra, J., et al. (2001). A compendium of gene expression in normal human tissues. Physiol. Genomics 7, 97-104.

Imai, Y., Shiratori, Y., Kato, N., Inoue, T., and Omata, M. (1999). Mutational inactivation of mitotic checkpoint genes, hsMAD2 and hBUB1, is rare in sporadic digestive tract cancers. Jpn. J. Cancer Res. 90, 837-840. doi:10.1111/j.13497006.1999.tb00824.x

Janssen, A., and Medema, R. H. (2013). Cancer: stress mixes chromosomes. Nature 494, 439-441. doi:10.1038/494439a

Jones, R. N., and Diez, M. (2004). The B chromosome database. Cytogenet. Genome Res. 106, 149-150. doi:10.1159/000079280

Jones, R. N., and Rees, H. (1982). B Chromosomes. London: Academic Press.

Katz, W., Weinstein, B., and Solomon, F. (1990). Regulation of tubulin levels and microtubule assembly in Saccharomyces cerevisiae: consequences of altered tubulin gene copy number. Mol. Cell. Biol. 10, 5286-5294.

Kingsbury, M. A., Friedman, B., McConnell, M. J., Rehen, S. K., Yang, A. H., Kaushal, D., et al. (2005). Aneuploid neurons are functionally active and integrated into brain circuitry. Proc. Natl. Acad. Sci. U.S.A. 102, 6143-6147. doi:10.1073/pnas.0408171102

Kirk, D., and Jones, R. N. (1970). Nuclear genetic activity in Bchromosome rye, in terms of the quantitative interrelationships between nuclear protein, nuclear RNA and histone. Chromosoma 31, 241-254. doi:10.1007/BF00285151

Kost-Alimova, M., Fedorova, L., Yang, Y., Klein, G., and Imreh, S. (2004) Microcell-mediated chromosome transfer provides evidence that polysomy promotes structural instability in tumor cell chromosomes through asynchronous replication and breakage within late-replicating regions. Genes Chromosomes Cancer 40, doi:10.1002/gcc.20054

Lee, A. J., Endesfelder, D., Rowan, A. J., Walther, A., Birkbak, N. J., Futreal, P. A., et al. (2011). Chromosomal instability confers intrinsic multidrug resistance. Cancer Res. 71, 1858-1870. doi:10.1158/00085472.CAN-10-3604

Lengauer, C., Kinzler, K. W., and Vogelstein, B. (1997). Genetic instability in colorectal cancers. Nature 386, 623-627. doi:10.1038/386623a0

Lengauer, C., Kinzler, K. W., and Vogelstein, B. (1998). Genetic instabilities in human cancers. Nature 396, 643-649. doi:10.1038/25292

Levan, A. (1956). Chromosomes in cancer tissue. Ann. N. Y. Acad. Sci.63, 774-792. doi:10.1111/j.17496632.1956.tb50892.x

Li, L. B., Chang, K. H., Wang, P. R., Hirata, R. K., Papayannopoulou, T., and Russell, D. W. (2012). Trisomy correction in Down syndrome induced pluripotent stem cells. Cell Stem Cell 11, 615-619. doi:10.1016/j.stem.2012.08.004

Li, R., Hehlmann, R., Sachs, R., and Duesberg, P. (2005). Chromosomal alterations cause the high rates and wide ranges of drug resistance in cancer cells. Cancer Genet. Cytogenet. 163, 44-56. doi:10.1016/ j.cancergencyto.2005.05.003

Lingle, W. L., Lukasiewicz, K., and Salisbury, J. L. (2005). Deregulation of the centrosome cycle and the origin of chromosomal instability in cancer. Adv. Exp. Med. Biol. 570, 393-421. doi:10.1007/1-4020-37643_14

Liu, X., Yu, X., Zack, D. J., Zhu, H., and Qian, J. (2008). TiGER: a database for tissue-specific gene expression and regulation. BMC Bioinformatics 9:271. doi:10.1186/1471-2105-9-271

Logarinho, E., Resende, T., Torres, C., and Bousbaa, H. (2008). The human spindle assembly checkpoint protein Bub3 is required for the establishment of efficient kinetochore-microtubule attachments. Mol. Biol. Cell 19, 1798-1813. doi:10.1091/mbc.E07-07-0633

Ly, P., Eskiocak, U., Kim, S. B., Roig, A. I., Hight, S. K., Lulla, D. R., et al. (2011). Characterization of aneuploid populations with trisomy 7 and 20 derived from diploid human colonic epithelial cells. Neoplasia 13, 348-357.

Mack, M., Gompel-Klein, P., Haase, E., Hietkamp, J., Ruhland, A., and Brendel, M. (1988). Genetic characterization of hyperresistance to formaldehyde and 4-nitroquinoline$\mathrm{N}$-oxide in the yeast Saccharomyces cerevisiae. Mol. Gen. Genet. 211, 260-265. doi:10.1007/BF00330602

Makino, S. (1956). Further evidence favoring the concept of the stem cell in ascites tumors of rats. Ann. N. Y. Acad. Sci. 63, 818-830. doi:10.1111/j.17496632.1956.tb50894.x

Martis, M. M., Klemme, S., BanaeiMoghaddam, A. M., Blattner, F. R., Macas, J., Schmutzer, T., et al. (2012). Selfish supernumerary chromosome reveals its origin as a mosaic of host genome and organellar sequences. Proc. Natl. Acad. Sci. U.S.A. 109, 13343-13346. doi:10.1073/pnas.1204237109

Matsumura, K., Kallioniemi, A., Kallioniemi, O., Chen, L., Smith, H. S., Pinkel, D., et al. (1992). Deletion of chromosome $17 \mathrm{p}$ loci in breast cancer cells detected by fluorescence in situ hybridization. Cancer Res. 52, 3474-3477.

Miao, V. P., Covert, S. F., and Vanetten, H. D. (1991a). A fungal gene for antibiotic resistance on a dispensable ("B") chromosome. Science 254, 1773-1776. doi:10.1126/science.1763326

Miao, V. P., Matthews, D. E., and Vanetten, H. D. (1991b). Identification and chromosomal locations of a family of cytochrome P-450 genes for pisatin detoxification in the fungus Nectria haematococca. Mol. Gen. Genet. 226, 214-223. doi:10.1007/BF00273606

Minissi, S., Degrassi, F., Tanzarella, C., and Gustavino, B. (1999). Direct and indirect nondisjunction in the origin of trisomy in cultured human lymphocytes. Mutagenesis 14, 557-562. doi:10.1093/mutage/14.6.557

Mitelman, F., Johansson, B., and Mertens, F. (2011). Mitelman Database of Chromosome Aberrations in Cancer. Available at: http://cgap.nci. nih.gov/Chromosomes/Mitelman

Mondal, G., Sengupta, S., Panda, C. K., Gollin, S. M., Saunders, W. S., and Roychoudhury, S. (2007). Overexpression of Cdc20 leads to impairment of the spindle assembly checkpoint and aneuploidization in oral cancer. Carcinogenesis 28, 81-92. doi:10.1093/carcin/ bgl100

Muller, H. J. (1964). The relation of recombination to mutational advance. Mutat. Res. 1, 2-9. doi:10.1016/0027-5107(64)90047-8

Musacchio, A., and Salmon, E. D. (2007). The spindle-assembly checkpoint in space and time. Nat. 
Rev. Mol. Cell Biol. 8, 379-393. doi:10.1038/nrm2163

Nicholson, J. M., and Cimini, D. (2011). How mitotic errors contribute to karyotypic diversity in cancer. Adv. Cancer Res. 112, 43-75. doi:10.1016/B978-0-12-3876881.00003-X

Nicholson, J. M., and Duesberg, P. (2009). On the karyotypic origin and evolution of cancer cells. Cancer Genet. Cytogenet. 194, 96-110. doi:10.1016/j.cancergencyto.2009. 06.008

Nicholson, J. M., Mattingly, A. J., Wangsa, D., Camps, J., Ried, T., and Cimini, D. (2012). Aneuploidy causes chromosome mis-segregation and karyotypedependent phenotypes in cancer cells. Mol. Biol. Cell 23(Suppl.). [Abstract No. 1938].

Ozery-Flato, M., Linhart, C., Trakhtenbrot, L., Izraeli, S., and Shamir, R. (2011). Large-scale analysis of chromosomal aberrations in cancer karyotypes reveals two distinct paths to aneuploidy. Genome Biol. 12, R61. doi:10.1186/gb-2011-12-6-r61

Pavelka, N., Rancati, G., Zhu, J., Bradford, W. D., Saraf, A., Florens, L., et al. (2010). Aneuploidy confers quantitative proteome changes and phenotypic variation in budding yeast. Nature 468, doi:10.1038/nature09529

Plowman, A. B., and Bougourd, S. M. (1994). Selectively advantageous effects of B chromosomes on germination behaviour in Allium schoenoprasum L. Heredity 72, 587-593. doi:10.1038/hdy.1994.81

Pollack, J. R., Sorlie, T., Perou, C. M., Rees, C. A., Jeffrey, S. S., Lonning, P. E., et al. (2002). Microarray analysis reveals a major direct role of DNA copy number alteration in the transcriptional program of human breast tumors. Proc. Natl. Acad. Sci. U.S.A. 99, doi:10.1073/pnas.162471999

Rabin, K. R., and Whitlock, J. A. (2009). Malignancy in children with trisomy 21. Oncologist 14, 164-173. doi:10.1634/theoncologist.20080217

Rancati, G., and Pavelka, N. (2013). Karyotypic changes as drivers and catalyzers of cellular evolvability: a perspective from non-pathogenic yeasts. Semin. Cell Dev. Biol. 24, 332-338. doi:10.1016/j.semcdb.2013.01.009

Rancati, G., Pavelka, N., Fleharty, B., Noll, A., Trimble, R., Walton, K., et al. (2008). Aneuploidy underlies rapid adaptive evolution of yeast cells deprived of a conserved cytokinesis motor. Cell 135, 879-893. doi:10.1016/j.cell.2008.09.039

Rehen, S. K., Yung, Y. C., McCreight, M. P., Kaushal, D., Yang, A. H., Almeida, B. S., et al. (2005). Constitutional aneuploidy in the normal human brain. J. Neurosci. 25, 2176-2180. doi:10.1523/ JNEUROSCI.4560-04.2005

Reish, O., Brosh, N., Gobazov, R., Rosenblat, M., Libman, V., and Mashevich, M. (2006). Sporadic aneuploidy in PHA-stimulated lymphocytes of Turner's syndrome patients. Chromosome Res. 14, 527-534. doi:10.1007/s10577-006-1050-9

Reish, O., Regev, M., Kanesky, A., Girafi, S., and Mashevich, M. (2011). Sporadic aneuploidy in PHA-stimulated lymphocytes of trisomies 21, 18, and 13. Cytogenet. Genome Res. 133, 184-189. doi:10.1159/000323504

Ried, T., Hu, Y., Difilippantonio, M. J., Ghadimi, B. M., Grade, M., and Camps, J. (2012). The consequences of chromosomal aneuploidy on the transcriptome of cancer cells. Biochim. Biophys. Acta 1819, 784-793. doi:10.1016/j.bbagrm.2012.02.020

Robinson, P. M., and Hewitt, G. M. (1976). Annual cycles in the incidence of b chromosomes in the grasshopper Myrmeleotettix maculatus (acrididae: orthoptera). Heredity (Edinb) 36, 399-412. doi:10.1038/hdy.1976.47

Roschke, A. V., Stover, K., Tonon, G., Schaffer, A. A., and Kirsch, I. R. (2002). Stable karyotypes in epithelial cancer cell lines despite high rates of ongoing structural and numerical chromosomal instability. Neoplasia 4, 19-31. doi:10.1038/sj.neo.7900197

Ryan, S. D., Britigan, E. M., Zasadil, L. M., Witte, K., Audhya, A., Roopra, A., et al. (2012). Up-regulation of the mitotic checkpoint component MAD1 causes chromosomal instability and resistance to microtubule poisons. Proc. Natl. Acad. Sci. U.S.A. 109, E2205-E2214. doi:10.1073/pnas.1201911109

Sato, M., Sekido, Y., Horio, Y., Takahashi, M., Saito, H., Minna, J. D., et al. (2000). Infrequent mutation of the hBUBl and hBUBR1 genes in human lung cancer. Jpn. J. Cancer Res. 91, 504-509. doi:10.1111/j.13497006.2000.tb00974.x

Selmecki, A., Forche, A., and Berman, J. (2006). Aneuploidy and isochromosome formation in drug-resistant Candida albicans. Science 313, 367-370. doi:10.1126/science. 1128242
Selmecki, A., Gerami-Nejad, M., Paulson, C., Forche, A., and Berman, J. (2008). An isochromosome confers drug resistance in vivo by amplification of two genes, ERG11 and TAC1. Mol. Microbiol. 68, 624-641. doi:10.1111/j.13652958.2008.06176.x

Selmecki, A. M., Dulmage, K., Cowen, L. E., Anderson, J. B., and Berman, J. (2009). Acquisition of aneuploidy provides increased fitness during the evolution of antifungal drug resistance. PLoS Genet. 5:e1000705. doi:10.1371/journal.pgen. 100 0705

Sheltzer, J. M., Blank, H. M., Pfau, S. J., Tange, Y., George, B. M., Humpton, T. J., et al. (2011). Aneuploidy drives genomic instability in yeast. Science 333, 1026-1030. doi:10.1126/science. 1206412

Silkworth, W. T., and Cimini, D. (2012). Transient defects of mitotic spindle geometry and chromosome segregation errors. Cell Div. 7, 19. doi:10.1186/1747-1028-7-19

Silkworth, W. T., Nardi, I. K., Scholl, L. M., and Cimini, D. (2009). Multipolar spindle pole coalescence is a major source of kinetochore mis-attachment and chromosome mis-segregation in cancer cells. PLoS ONE 4:e6564. doi:10.1371/journal.pone. 0006564

Smith, L., Plug, A., and Thayer, M. (2001). Delayed replication timing leads to delayed mitotic chromosome condensation and chromosomal instability of chromosome translocations. Proc. Natl. Acad. Sci. U.S.A. 98, 13300-13305. doi:10.1073/pnas.241355098

Sotillo, R., Hernando, E., DiazRodriguez, E., Teruya-Feldstein, J., Cordon-Cardo, C., Lowe, S. W., et al. (2007). MAD2 overexpression promotes aneuploidy and tumorigenesis in mice. Cancer Cell 11, 9-23. doi:10.1016/j.ccr.2006.10.019

Sotillo, R., Schvartzman, J. M., Socci, N. D., and Benezra, R. (2010). MAD2induced chromosome instability leads to lung tumour relapse after oncogene withdrawal. Nature 464, 436-440. doi:10.1038/nature08803

Staub, R. W. (1987). Leaf striping correlated with the presence of $\mathrm{B}$ chromosomes in maize. J. Hered. 78, 71-74.

Stoffregen, E. P., Donley, N., Stauffer, D., Smith, L., and Thayer, M. J. (2011). An autosomal locus that controls chromosome-wide replication timing and mono-allelic expression. Hum. Mol. Genet. 20, 2366-2378. doi:10.1093/hmg/ddr138
Storchova, Z., and Kuffer, C. (2008). The consequences of tetraploidy and aneuploidy. J. Cell. Sci. 121, 3859-3866. doi:10.1242/jcs.039537

Sumner, A. T. (2003). Chromosomes: Organization and Function. Malden, MA: Blackwell Publishing Inc.

Tabach, Y., Kogan-Sakin, I., Buganim, Y., Solomon, H., Goldfinger, N., Hovland, R., et al. (2011). Amplification of the $20 \mathrm{q}$ chromosomal arm occurs early in tumorigenic transformation and may initiate cancer. PLoS ONE 6:e14632. doi:10.1371/journal.pone.0014632

Tang, Y. C., Williams, B. R., Siegel, J. J., and Amon, A. (2011). Identification of aneuploidyselective antiproliferation compounds. Cell 144, 499-512. doi:10.1016/j.cell.2011.01.017

Thayer, M. J. (1996). Regulation of tissue-specific gene expression in microcell hybrids. Methods 9, 30-37. doi:10.1006/meth.1996.0005

Thayer, M. J. (2012). Mammalian chromosomes contain cis-acting elements that control replication timing, mitotic condensation, and stability of entire chromosomes. Bioessays 34, 760-770. doi:10.1002/bies.201200035

Thompson, S. L., and Compton, D. A. (2008). Examining the link between chromosomal instability and aneuploidy in human cells. J. Cell Biol. 180, 665-672. doi:10.1083/jcb.200712029

Thompson, S. L., and Compton, D. A. (2010). Proliferation of aneuploid human cells is limited by a p53-dependent mechanism. J. Cell Biol. 188, 369-381. doi:10.1083/jcb.200905057

Tighe, A., Johnson, V. L., Albertella, M., and Taylor, S. S. (2001). Aneuploid colon cancer cells have a robust spindle checkpoint. EMBO Rep. 2, 609-614. doi:10.1093/emboreports/kve127

Torres, E. M., Sokolsky, T., Tucker, C. M., Chan, L. Y., Boselli, M., Dunham, M. J., et al. (2007). Effects of aneuploidy on cellular physiology and cell division in haploid yeast. Science 317, 916-924. doi:10.1126/science.1142210

Torres, E. M., Williams, B. R., and Amon, A. (2008). Aneuploidy: cells losing their balance. Genetics 179, 737-746. doi:10.1534/genetics.108.090878

Upender, M. B., Habermann, J. K., McShane, L. M., Korn, E. L., Barrett, J. C., Difilippantonio, M. J., et al. (2004). Chromosome transfer induced aneuploidy results in complex dysregulation of the cellular transcriptome in immortalized 
and cancer cells. Cancer Res 64, Yoshida, K., Terai, Y., Mizoiri, S., Aibara, 6941-6949.

Vincent, M. D. (2011). Cancer: beyond speciation. Adv. Cancer Res. 112, 283-350. doi:10.1016/B978-0-12387688-1.00010-7

Winge, O. (1930). Zytologische Untersuchungen ueber die Natur maligner Tumoren. II. Teerkarzinome bei Maeusen. Z. Zellforsch. Mikrosk. Anat. 10, 683-735. doi:10.1007/BF00372971

Yamaguchi, K., Okami, K., Hibi, K., Wehage, S. L., Jen, J., and Sidransky, D. (1999). Mutation analysis of hBUB1 in aneuploid HNSCC and lung cancer cell lines. Cancer Lett. 139, 183-187. doi:10.1016/S03043835(99)00035-X et al. (2011). B Chromosomes have a functional effect on female sex determination in Lake Victoria cichlid fishes. PLoS Genet. 7:e1002203. doi:10.1371/journal.pgen.1002203

Yuan, B., Xu, Y., Woo, J. H., Wang, Y., Bae, Y. K., Yoon, D. S., et al. (2006). Increased expression of mitotic checkpoint genes in breast cancer cells with chromosomal instability. Clin. Cancer Res. 12, 405-410. doi:10.1158/10780432.CCR-05-0903

Zasadil, L. M., Britigan, E. M., and Weaver, B. A. (2013). $2 \mathrm{n}$ or not 2n: aneuploidy, polyploidy and chromosomal instability in
Yoshida, K., Terai, Y., Mizoiri, S., Aibara,
M., Nishihara, H., Watanabe, M., primary and tumor cells. Semin. Cell Dev. Biol. 24, 370-379. doi:10.1016/j.semcdb.2013.02.001

Zhu, J., Pavelka, N., Bradford, W. D., Rancati, G., and Li, R. (2012). Karyotypic determinants of chromosome instability in aneuploid budding yeast. PLoS Genet. 8:e1002719. doi:10.1371/journal.pgen.100 2719

Conflict of Interest Statement: The authors declare that the research was conducted in the absence of any commercial or financial relationships that could be construed as a potential conflict of interest.
Received: 18 April 2013; accepted: 22 May 2013; published online: 07 June 2013.

Citation: Nicholson JM and Cimini D (2013) Cancer karyotypes: survival of the fittest. Front. Oncol. 3:148. doi: 10.3389/fonc. 2013.00148

This article was submitted to Frontiers in Molecular and Cellular Oncology, a specialty of Frontiers in Oncology.

Copyright (C) 2013 Nicholson and Cimini. This is an open-access article distributed under the terms of the Creative Commons Attribution License, which permits use, distribution and reproduction in other forums, provided the original authors and source are credited and subject to any copyright notices concerning any third-party graphics etc. 